\title{
BMJ Open Loneliness among older adults in the community during COVID-19: a cross- sectional survey in Canada
}

Rachel D Savage, ${ }^{1,2}$ Wei Wu, ${ }^{1}$ Joyce Li, ${ }^{1}$ Andrea Lawson, ${ }^{1}$ Susan E Bronskill (D) , $, 1,2,3$ Stephanie A Chamberlain, ${ }^{4}$ Jim Grieve, ${ }^{5}$ Andrea Gruneir, ${ }^{1,2,4}$ Christina Reppas-Rindlisbacher, ${ }^{1,6}$ Nathan M Stall, ${ }^{1,3,6}$ Paula A Rochon (10) 1,2,3,6

To cite: Savage RD, Wu W, Li J, et al. Loneliness among older adults in the community during COVID-19: a cross-sectional survey in Canada. BMJ Open 2021;11:e044517. doi:10.1136/ bmjopen-2020-044517

- Prepublication history for this paper is available online. To view these files, please visit the journal online (http://dx.doi. org/10.1136/bmjopen-2020044517).

Received 11 September 2020 Revised 25 February 2021 Accepted 05 March 2021

Check for updates

(C) Author(s) (or their employer(s)) 2021. Re-use permitted under CC BY-NC. No commercial re-use. See rights and permissions. Published by BMJ.

${ }^{1}$ Women's College Research Institute, Women's College Hospital, Toronto, Ontario, Canada

${ }^{2}$ ICES, Toronto, Ontario, Canada ${ }^{3}$ Institute of Health Policy, Management and Evaluation, Dalla Lana School of Public Health, University of Toronto, Toronto, Ontario, Canada ${ }^{4}$ Department of Family Medicine, University of Alberta, Edmonton, Alberta, Canada

${ }^{5}$ RTOERO, Toronto, Ontario,

Canada

${ }^{6}$ Division of Geriatric Medicine, Department of Medicine, University of Toronto, Toronto, Ontario, Canada

Correspondence to Dr Paula A Rochon; paula.rochon@wchospital.ca

\section{ABSTRACT}

Objective Physical distancing and stay-at-home measures implemented to slow transmission of novel coronavirus disease (COVID-19) may intensify feelings of Ioneliness in older adults, especially those living alone. Our aim was to characterise the extent of loneliness during the first wave in a sample of older adults living in the community and assess characteristics associated with Ioneliness.

Design Online cross-sectional survey between 6 May and 19 May 2020.

Setting Ontario, Canada.

Participants Convenience sample of members of a national retired educators' organisation.

Primary outcome measures Self-reported loneliness, including differences between women and men. Results 4879 respondents (71.0\% women; 67.4\% 65-79 years) reported that in the preceding week, $43.1 \%$ felt lonely at least some of the time, including $8.3 \%$ who felt lonely always or often. Women had increased odds of loneliness compared with men, whether living alone (adjusted OR (aOR) 1.52, 95\% Cl 1.13 to 2.04) or with others $(2.44,95 \% \mathrm{Cl} 2.04$ to 2.92$)$. Increasing age group decreased the odds of loneliness (aOR 0.69 (95\% Cl 0.59 to 0.81$) 65-79$ years and 0.50 (95\% Cl 0.39 to 0.65$)$ $80+$ years compared with $<65$ years). Living alone was associated with loneliness, with a greater association in men (aOR 4.26, 95\% Cl 3.15 to 5.76) than women (aOR $2.65,95 \% \mathrm{Cl} 2.26$ to 3.11 ). Other factors associated with Ioneliness included: fair or poor health (aOR 1.93, 95\% Cl 1.54 to 2.41 ), being a caregiver (aOR $1.18,95 \% \mathrm{Cl} 1.02$ to 1.37), receiving care (aOR $1.47,95 \% \mathrm{Cl} 1.19$ to 1.81 ), high concern for the pandemic (aOR 1.55, 95\% $\mathrm{Cl} 1.31$ to 1.84), not experiencing positive effects of pandemic distancing measures (aOR 1.94, 95\% Cl 1.62 to 2.32) and changes to daily routine (aOR $2.81,95 \% \mathrm{Cl} 1.96$ to 4.03 ).

Conclusions While many older adults reported feeling Ionely during COVID-19, several characteristics—such as being female and living alone-increased the odds of loneliness. These characteristics may help identify priorities for targeting interventions to reduce loneliness.

\section{BACKGROUND}

As data emerge on how common, yet harmful, it is to be lonely, loneliness is increasingly recognised as a public health priority. In
Strengths and limitations of this study

- The study leveraged a strong community-based partnership to obtain timely data from a large sample of older Canadians on the impacts of the first wave of COVID-19.

- The study evaluated the association between sociodemographic characteristics, social support, and COVID-19-related attitudes and behaviours, and Ioneliness, stratified by sex and overall. The data were based on a convenience sample of retired educational staff, who are not fully representative of the Canadian population.

- The perspectives of vulnerable groups who may be at greater risk for loneliness (eg, those with severe mental health illness, low income, no home internet access, and so on) are likely under-represented in this sample.

the USA, more than $40 \%$ of respondents to the nationally representative Health and Retirement Study reported feeling lonely. ${ }^{1}$ In Canada, one in four older women and one in five older men report feeling lonely at least some of the time. ${ }^{2}$ While feelings of loneliness can occur at any age, research has shown that rates of loneliness follow a nonlinear U-shaped distribution, with the highest levels reported in young $(<25$ years $)$ and older ( $>65$ years) adults. ${ }^{3}$ While predisposing factors differ by life stage, older adults are at increased risk because they are more likely to experience events such as retirement, chronic illness, widowhood and living alone. ${ }^{4}$ Women report higher rates of loneliness than men, ${ }^{24}$ possibly due to their longer life expectancy and greater likelihood of outliving their spouse, resulting in prolonged widowhood, ${ }^{56}$ their caregiver roles, ${ }^{2}{ }^{8}$ lower incomes ${ }^{9}$ and their greater tendency to acknowledge feeling lonely. ${ }^{6}$ Addressing loneliness is important because of its profound impact on health and well-being, including increased risk for 
premature death, ${ }^{10}{ }^{11}$ cardiovascular disease, depression, dementia and even suicide. ${ }^{12-18}$

The novel coronavirus pandemic (COVID-19) and accompanying physical distancing and stay-at-home measures (ie, closure of non-essential businesses and public spaces, as well as recommendations to practise physical distancing with anyone outside the home) are expected to intensify feelings of loneliness. Previous infectious disease outbreaks and pandemics have demonstrated increases in loneliness, anxiety and depression from quarantine-induced social isolation. ${ }^{19}{ }^{20}$ Emerging research from the early stages of the COVID-19 pandemic support this hypothesis, ${ }^{21}$ with several studies demonstrating elevated rates of loneliness, ${ }^{22-24}$ psychological distress, ${ }^{2526}$ and anxiety, depression and stress ${ }^{27} 28$ during lockdown periods.

Understanding how older adults have been impacted by COVID-19 is vital to address their needs promptly and effectively and prevent unnecessary harms as the pandemic persists. Cross-sectional studies published as early as April 2020 examined public concerns regarding COVID-19 (eg, becoming infected, reduced healthcare access) and its impact on daily life. ${ }^{29}{ }^{30}$ While valuable, these studies were conducted prior to or on the cusp of the implementation of physical distancing and stay-athome measures, did not report on mental health, underrepresented older adults, ${ }^{29}$ a key high-risk group and did not explore important differences between women and men. More recently, McGinty et al published prevalence estimates of psychological distress and loneliness in the USA; although subgroup analyses focused on psychological distress rather than loneliness. ${ }^{25}$

More data on loneliness in older adults during COVID-19 continue to emerge as the pandemic unfolds, ${ }^{24} 31-34$ yet important knowledge gaps remain. A key gap is whether older women and men have shared, or unique, risk factors for loneliness during the pandemic. Before COVID-19, it has been shown that while there are common contributors to loneliness in older adults, like widowhood or declining health, some risk factors affect the sexes differently. For example, mobility problems have been shown to be a strong predictor of loneliness in women, while a reduced social network strongly predicts loneliness in men. ${ }^{35}$ There are also comparatively little data on the relationship between COVID-19-specific factors (eg, level of concern, impact to daily life, COVID-19 infection, and

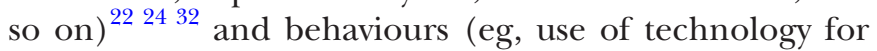
social connection) with loneliness in general, but particularly in older adults. Timely data relevant to older women and men are needed to inform public health responses and healthcare delivery.

We conducted an online cross-sectional survey to assess how the first wave of the COVID-19 pandemic affected older adults living in the community in Canada. Our objective was to characterise the extent of loneliness in older adults, including differences between women and men, and examine factors associated with loneliness to identify groups likely to benefit most from intervention.
We hypothesised that loneliness would be common, particularly in women and those living alone, and that higher pandemic concern would increase loneliness.

\section{METHODS}

\section{Study design and setting}

A closed, online cross-sectional survey was administered to members of the RTOERO (formerly known as the Retired Teachers of Ontario) between 6 May and 19 May 2020. At this time in Ontario, Canada, physical distancing measures (eg, lockdown) had been in place for about 7 weeks; daily case and death counts were in decline after peaks in late April; and outbreaks in long-term care homes were a focus of news headlines (figure 1 for timeline).

RTOERO is a voluntary membership organisation of more than 81000 retired educators, administrators and educational support staff from child care, K-12 and postsecondary settings that provides group health insurance benefits, as well as other programmes and services, to the broader education community (https://www.rtoero.ca). Members were invited to participate by email from RTOERO's chief executive officer. Two reminder emails were sent at 7 and 10 days. The survey was not publicly advertised. All members were eligible to participate if they had a registered email address $(\sim 62000)$. Study materials were provided in English and French. Our study design and reporting followed the Checklist for Reporting Results of Internet E-Surveys. ${ }^{36}$

A link to a study information sheet was provided on the survey's home page and informed consent was obtained electronically. Participation was voluntary, and no incentives were provided. Minimal identifying personal information was collected (eg, first three digits of postal code).

\section{Questionnaire}

The questionnaire was developed with RTOERO leadership and included 32 questions (online supplemental appendix). Several questions were adapted with permission from the Stanford Coronavirus Survey (https://pcrt. stanford.edu/covid). Questions examined the impact of COVID-19 on daily life; loneliness; and the use of digital technologies for social connectivity. We used a singleitem, direct measure of loneliness by asking respondents, 'In the past seven days, which statement best applies?' (I did not feel lonely; I felt lonely 1 or 2 days; I felt lonely several days; I felt lonely most days; I felt lonely every day). This approach was adapted from the Canadian Longitudinal Study on Aging (CLSA) ${ }^{2}$ and the UK's Community Life Survey ${ }^{37}$ which measure loneliness by directly asking, 'How often do you feel lonely?' (often/always, some of the time, occasionally, hardly ever or never). We chose this approach because it allowed respondents to self-report on loneliness, anchored their response to a time during the pandemic stay-at-home measures and was considered more suitable for the pandemic context, where asking indirectly about feeling 'left out' to infer 


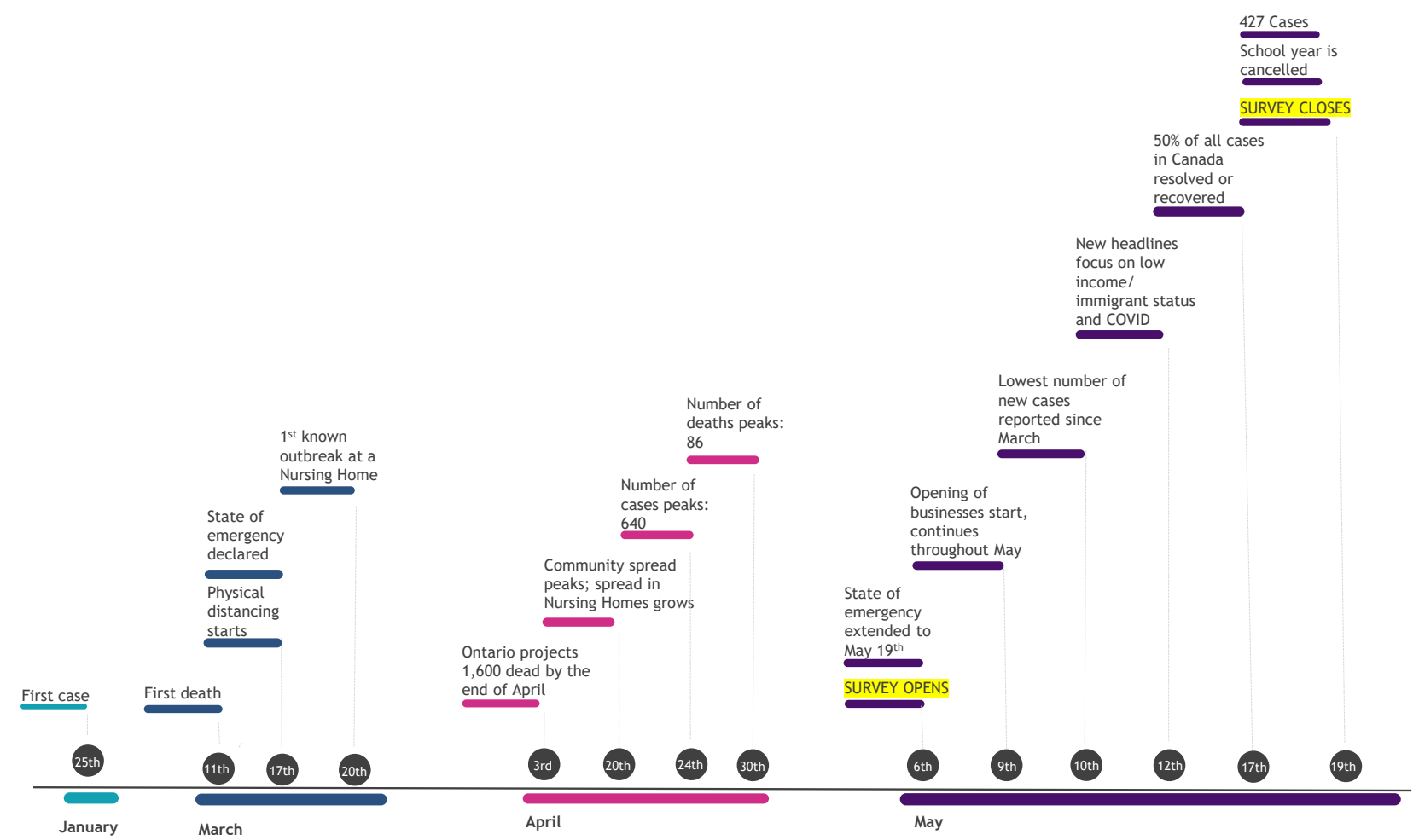

Figure 1 Timeline of COVID-19 in Ontario, Canada's largest province. Physical distancing measures beginning 17 March included closure of all indoor recreational facilities, public libraries, theatres, cinemas, bars and restaurants. Publicly funded schools were closed by this point as well, and all employers in Ontario were asked to facilitate virtual work arrangements for employees. Remaining non-essential businesses were closed on 25 March. Gatherings of more than five people were prohibited on 28 March. On 30 March, Ontario's Chief Medical Officer of Health strongly recommended individuals over 70 years of age or those with compromised immune systems or underlying medical conditions to stay at home. Source: CIHI, COVID-19 Intervention Scan, accessed 11 August 2020, https://www.cihi.ca/en/covid-19-intervention-scan

loneliness may be less relevant as distancing and stay-athome measures were universally applied.

Respondents were also asked about their history of COVID-19 symptoms and testing, the extent to which they were practising physical distancing and stay-at-home measures, and sociodemographic characteristics (ie, age, sex, ethnicity, language, health status and location of residence). The ethnic response categories we used mirrored those used in Canada's National Health Survey. ${ }^{38}$ The questionnaire was pretested in English with 18 RTOERO board members and staff, and in French by one staff member, for usability, technical functionality, clarity, flow, sensitive questions and timing. Pretest results were not included in the final analysis.

\section{Patient and public involvement}

As noted above, RTOERO leadership (which comprises members of RTOERO) was involved in all aspects of the study, including questionnaire development, pretesting and participant recruitment. Preliminary results were shared with the team and feedback was incorporated into the final analysis and manuscript. RTOERO's chief executive officer is a coauthor (JG) and critically reviewed the manuscript. Results were shared with RTOERO members through a webinar in the fall of 2020.

\section{Data collection}

The questionnaire was administered using SimpleSurvey. Data were stored in an encrypted, password-protected form on the secure SimpleSurvey server and were downloaded to the secure, password-protected Women's College Hospital server accessible to authorised team members. All questions were optional, so completeness checks were not performed; although respondents were reminded of unanswered questions before proceeding to the next section to minimise incomplete data. We used adaptive questioning to reduce the complexity of questions. ${ }^{36}{ }^{39}$ Respondents were able to save their responses and return to the survey later to complete it. The survey completion rate was the number of respondents who finished the survey divided by the number consenting to participate. ${ }^{36}$ Surveys were only analysed if the respondent clicked 'Submit' and responded to more than one question.

\section{Exposures}

Sociodemographic characteristics—sex, age, living alone, ethnicity, rural residence, health status and caregiver status-were collected based on factors previously reported to be associated with loneliness. ${ }^{45}$ We additionally collected self-reported measures of social 
support-communication frequency, receiving offers of assistance and social media use-as well as attitudes and behaviours towards COVID-19 hypothesised to contribute to loneliness, including level of concern, change in daily routine, extent of physical distancing and perceived positive effects of distancing measures. Variable definitions are presented in the online supplemental eMethods.

\section{Outcome}

Our primary outcome was loneliness. Respondents were categorised as lonely 'always or often' if they reported feeling lonely every or most days in the preceding 7 days; lonely 'some of the time' if they reported feeling lonely on 1-2 or several days; and 'not lonely' if they reported they had not felt lonely at all. We further collapsed the first two categories to create a dichotomous variable for loneliness, where respondents were classified as lonely if they reported feeling lonely on 1 or more days in the preceding 7 days. ${ }^{237}$

\section{Analysis \\ $\mathrm{X}^{2}$ tests were used to identify sex differences. To iden- tify predictors of loneliness for older women and men, exploratory analyses using sex-stratified and sex-pooled multivariable logistic regression models were conducted. In the sex-stratified regression analysis, we calculated unadjusted and minimally adjusted (age and health status) models, and used findings to inform which inter- actions to test for in the sex-pooled analysis. In the sex- pooled model, we additionally adjusted for all covariates and formally tested for sex interactions with explanatory factors, including age group, living alone, communica- tion frequency, receiving offers of assistance, change in daily routine and perceived positive effects of distancing measures, using interaction terms. Statistical tests were two sided, with $\mathrm{p}<0.05$ interpreted as statistically signifi- cant. Analyses were performed using SAS V.9.4.}

\section{RESULTS}

Overall, 5556 RTOERO members responded to the survey, of which 5509 provided consent. A total of 4891 surveys were submitted for a completion rate of $88.8 \%$. We excluded 12 respondents who responded to $\leq 1$ survey question, leaving 4879 respondents included in the analysis.

\section{Characteristics}

Most respondents were women $(3421 / 4818(71.0 \%))$, between the ages of 65 and 79 years $(3279 / 4863(67.4 \%))$ and completed the survey in English (97.6\%) (table 1). They were similar to the broader RTOERO membership in terms of sex ( $67 \%$ female), age distribution $(14.5 \%<65$ years; $64 \% 65-79$ years; $21.5 \% \geq 80$ years) and preferred language (95\% English) (J Grieve, personal communication). One-third of female respondents lived alone $(1138 / 3356(33.9 \%))$ compared with one-fifth of men $(266 / 1351(19.7 \%))$. Respondents were predominantly white $(4454 / 4861(91.6 \%))$ and in good self-reported health $(4370 / 4873(89.7 \%))$.

Less than $5 \%(236 / 4790(4.9 \%))$ reported a cold or influenza-like illness in the preceding month. Overall, 8 of 4861 respondents tested positive for COVID-19 (0.2\%). Most respondents strongly agreed that the COVID-19 pandemic had changed their daily routine $(67.5 \%$ females vs $63.2 \%$ males, $\mathrm{p}=0.0047$ ). Additional data on the impact of COVID-19 are reported in online supplemental table 1 and figure 1.

\section{Loneliness during COVID-19}

Overall, $43.1 \%$ of respondents felt lonely at least some of the time (34.8\% some of the time and $8.3 \%$ always or often) (table 2). Women were more likely to report feeling lonely than males $(p<0.001)$. Strategies to avoid feeling lonely included connecting with a friend or family member $(82.1 \%$ women vs $70.7 \%$ men, $\mathrm{p}<0.001)$ and getting fresh air $(65.3 \%$ vs $61.9 \%, \mathrm{p}=0.025)$. Seven per cent $(7.1 \%)$ described other strategies, such as reading, housework and/or gardening and practising their faith. Most participants frequently spoke with a friend, family member or neighbour, although a small proportion $(0.4 \%)$ had no connection at all. Many used social networking websites or apps $(87.3 \%$ females vs $78.2 \%$ males, $\mathrm{p}<0.001)$.

\section{Sex-stratified model}

Most factors associated with loneliness were shared among women and men (table 3). Older age significantly reduced the odds of loneliness in both sexes after adjustment for self-reported health status. Living alone was associated with loneliness in both women and men; although the association was greater in men (adjusted OR (aOR) 3.86 (95\% CI 2.88 to 5.18) vs aOR 2.50 (95\% CI 2.14 to 2.92)). Self-reported poor health and higher concern for the pandemic were also associated with loneliness, as were experiencing change to a daily routine, and not experiencing any positive effects or 'silver linings' of pandemic distancing measures; effect sizes varied by sex. Among women, receiving offers of assistance (aOR 0.79, $95 \%$ CI 0.69 to 0.91 ) and communicating more often with a friend, family member or neighbour (aOR $0.47,95 \%$ CI 0.34 to 0.66 ) reduced the odds of loneliness.

\section{Sex-pooled model}

Women had increased odds of loneliness compared with men, irrespective of living arrangement (aOR 1.52 (95\% CI 1.13 to 2.04) living alone; aOR 2.44 (95\% CI 2.04 to 2.92) living with others) (table 4). Increasing age group was associated with decreasing odds of loneliness. The association of living alone with loneliness was significantly greater for men than women (aOR 4.26 (95\% CI 3.15 to 5.76 ) vs 2.65 (95\% CI 2.26 to 3.11 ), $\mathrm{p}=0.006$ for interaction term). Additional characteristics associated with loneliness included: self-reported fair/poor health (aOR $1.93,95 \%$ CI 1.54 to 2.41), being a caregiver (aOR 1.18, 95\% CI 1.02 to 1.37 ) and receiving care from a caregiver (aOR 1.47, 95\% CI 1.19 to 1.81). Pandemic-related factors associated with an increased odds of loneliness included 
Table 1 Sociodemographic characteristics of older female and male survey respondents

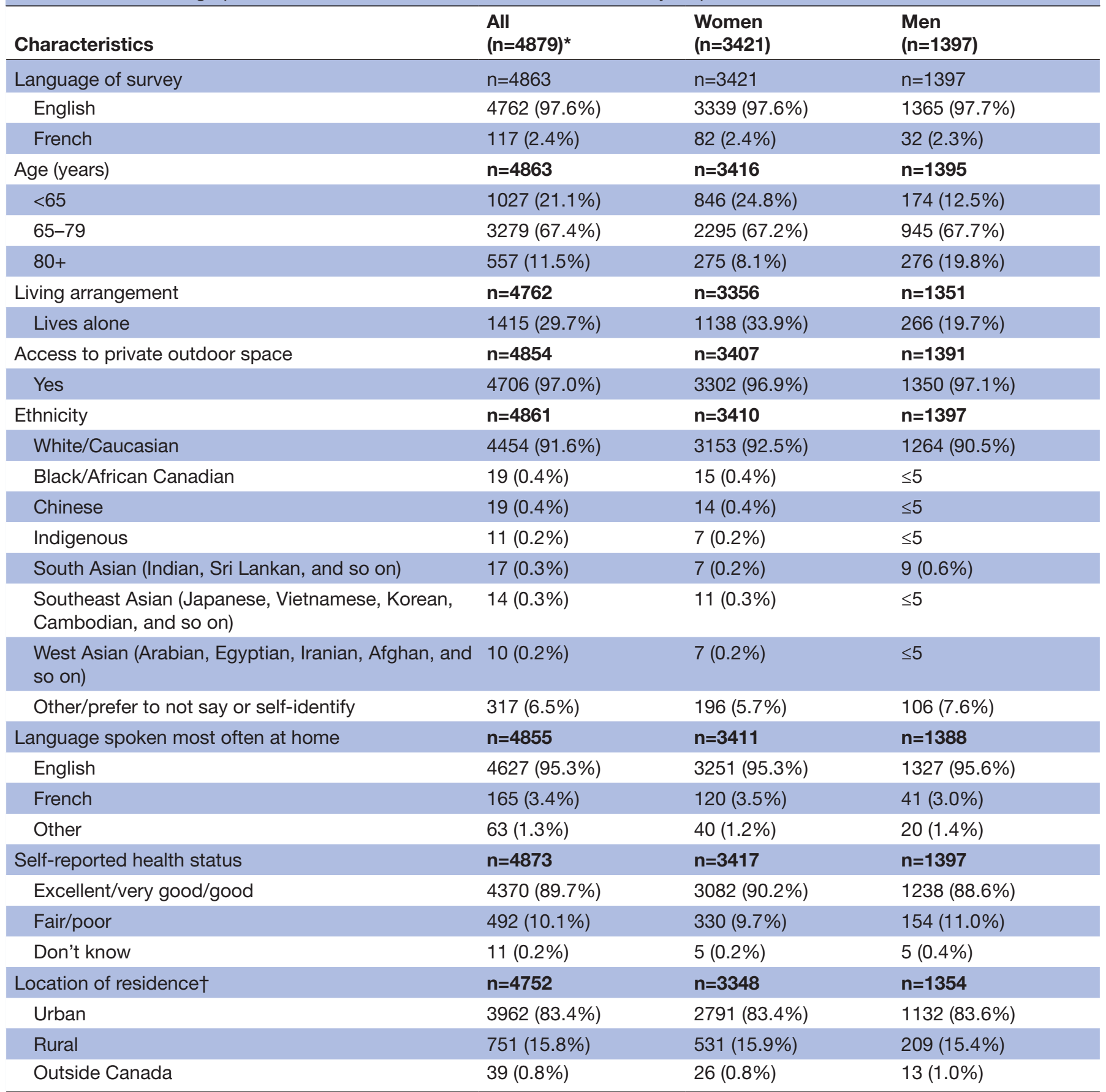

*61 respondents did not identify their gender.

†4405 (92.7\%) respondents resided in Ontario and 308 (6.5\%) in another Canadian province or territory.

having a high concern for the pandemic (aOR 1.55, 95\% CI 1.31 to 1.84 ), not experiencing any positive effects or 'silver linings' of pandemic distancing measures (aOR 1.94, 95\% CI 1.62 to 2.32) and experiencing change to a daily routine (aOR 2.81, 95\% CI 1.96 to 4.03 ). Non-white ethnicity (aOR $0.71,95 \%$ CI 0.54 to 0.94 ), high frequency of communication (aOR $0.55,95 \%$ CI 0.43 to 0.72 ) and receiving offers of assistance (aOR 0.79 , 95\% CI 0.69 to $0.90)$ reduced the odds of loneliness. None of the other sex-based interactions we explored with explanatory factors were significant. Social media use was not associated with loneliness (aOR 1.13, 95\% CI 0.94 to 1.36 ) and the addition of an interaction term between social media use and age was similarly not significant.

\section{DISCUSSION}

In a survey of 4879 older women and men, we found that loneliness was common during the COVID-19 pandemic, with more than one-third $(34.8 \%)$ of respondents 
Table 2 Loneliness and social connection in a sample of older Canadians, May 2020

\begin{tabular}{|c|c|c|c|c|}
\hline & $\begin{array}{l}\text { All } \\
(n=4879)^{*}\end{array}$ & $\begin{array}{l}\text { Women } \\
(\mathrm{n}=3421)\end{array}$ & $\begin{array}{l}\text { Men } \\
(n=1397)\end{array}$ & $P$ value \\
\hline Self-reported loneliness in past 7 days & $\mathrm{n}=4840$ & $n=3398$ & $n=1383$ & \\
\hline Did not feel lonely & $2675(55.3 \%)$ & $1684(49.6 \%)$ & $958(69.3 \%)$ & $<0.001$ \\
\hline Lonely some of the time & $1684(34.8 \%)$ & $1360(40.0 \%)$ & $307(22.2 \%)$ & \\
\hline Lonely always or often & $404(8.3 \%)$ & $315(9.3 \%)$ & $83(6.0 \%)$ & \\
\hline Don't know & $77(1.6 \%)$ & $39(1.1 \%)$ & $35(2.5 \%)$ & \\
\hline \multicolumn{5}{|l|}{ Strategies used to avoid feeling lonely $\dagger$} \\
\hline Connect with a friend or family member & $3841(78.7 \%)$ & $2808(82.1 \%)$ & $988(70.7 \%)$ & $<0.001$ \\
\hline Get fresh air & $3134(64.2 \%)$ & $2235(65.3 \%)$ & $865(61.9 \%)$ & 0.025 \\
\hline Stay busy with work or projects & $1855(38.0 \%)$ & $1275(37.3 \%)$ & $563(40.3 \%)$ & 0.049 \\
\hline Get active & $1632(33.5 \%)$ & $1137(33.2 \%)$ & $470(33.6 \%)$ & 0.785 \\
\hline Try to get proper rest and sleep & $1221(25.0 \%)$ & $806(23.6 \%)$ & $397(28.4 \%)$ & $<0.001$ \\
\hline Engage in a hobby & $1012(20.7 \%)$ & $704(20.6 \%)$ & $297(21.3 \%)$ & 0.597 \\
\hline Spend time with my pet & $612(12.5 \%)$ & $473(13.8 \%)$ & $129(9.2 \%)$ & $<0.001$ \\
\hline Other & 347 (7.1\%) & $248(7.3 \%)$ & $95(6.8 \%)$ & 0.582 \\
\hline $\begin{array}{l}\text { Frequency of speaking with a friend, family } \\
\text { member or neighbour }\end{array}$ & $n=4865$ & $n=3412$ & $n=1394$ & \\
\hline Not at all & $18(0.4 \%)$ & $4(0.1 \%)$ & $13(0.9 \%)$ & $<0.001$ \\
\hline $1-4$ times & $1401(28.8 \%)$ & 845 (24.8\%) & $535(38.4 \%)$ & \\
\hline $5-7$ times & $3446(70.8 \%)$ & $2563(75.1 \%)$ & $846(60.7 \%)$ & \\
\hline $\begin{array}{l}\text { Uses social networking websites or apps to } \\
\text { communicate with friends and family }\end{array}$ & $n=4868$ & $n=3418$ & $n=1394$ & \\
\hline Yes & $4113(84.5 \%)$ & $2983(87.3 \%)$ & $1090(78.2 \%)$ & $<0.001$ \\
\hline No & $751(15.4 \%)$ & $434(12.7 \%)$ & $301(21.6 \%)$ & \\
\hline Don't know & $4(0.1 \%)$ & $1(0.0 \%)$ & $3(0.2 \%)$ & \\
\hline \multicolumn{5}{|l|}{ Apps used $\dagger$} \\
\hline Facebook & $3031(62.1 \%)$ & $2235(65.3 \%)$ & 768 (55.0\%) & $<0.001$ \\
\hline Zoom & 2558 (52.4\%) & 1918 (56.1\%) & $617(44.2 \%)$ & $<0.001$ \\
\hline FaceTime & $2444(50.1 \%)$ & $1874(54.8 \%)$ & $546(39.1 \%)$ & $<0.001$ \\
\hline WhatsApp & $1182(24.2 \%)$ & $931(27.2 \%)$ & $239(17.1 \%)$ & $<0.001$ \\
\hline Instagram & $1125(23.1 \%)$ & $914(26.7 \%)$ & $201(14.4 \%)$ & $<0.001$ \\
\hline Skype & $772(15.8 \%)$ & $523(15.3 \%)$ & $244(17.5 \%)$ & 0.061 \\
\hline Twitter & $575(11.8 \%)$ & $429(12.5 \%)$ & $141(10.1 \%)$ & 0.017 \\
\hline Google Hangouts/Meet & $322(6.6 \%)$ & $255(7.5 \%)$ & $64(4.6 \%)$ & $<0.001$ \\
\hline Houseparty & $212(4.4 \%)$ & $178(5.2 \%)$ & $34(2.4 \%)$ & $<0.001$ \\
\hline Other & $368(7.5 \%)$ & 275 (8.0\%) & $89(6.4 \%)$ & 0.047 \\
\hline \multicolumn{5}{|l|}{ Devices used $\dagger$} \\
\hline Smartphone & 3026 (62.0\%) & 2204 (64.4\%) & 791 (56.6\%) & $<0.001$ \\
\hline Desktop/laptop & 2579 (52.9\%) & $1704(49.8 \%)$ & $846(60.6 \%)$ & $<0.001$ \\
\hline Landline telephone & 2528 (51.8\%) & $1776(51.9 \%)$ & 714 (51.1\%) & 0.612 \\
\hline Tablet & $2283(46.8 \%)$ & $1659(48.5 \%)$ & $594(42.5 \%)$ & $<0.001$ \\
\hline Other & $172(3.5 \%)$ & $136(4.0 \%)$ & $33(2.4 \%)$ & 0.006 \\
\hline
\end{tabular}

*61 respondents did not identify their gender.

†Categories not mutually exclusive. 


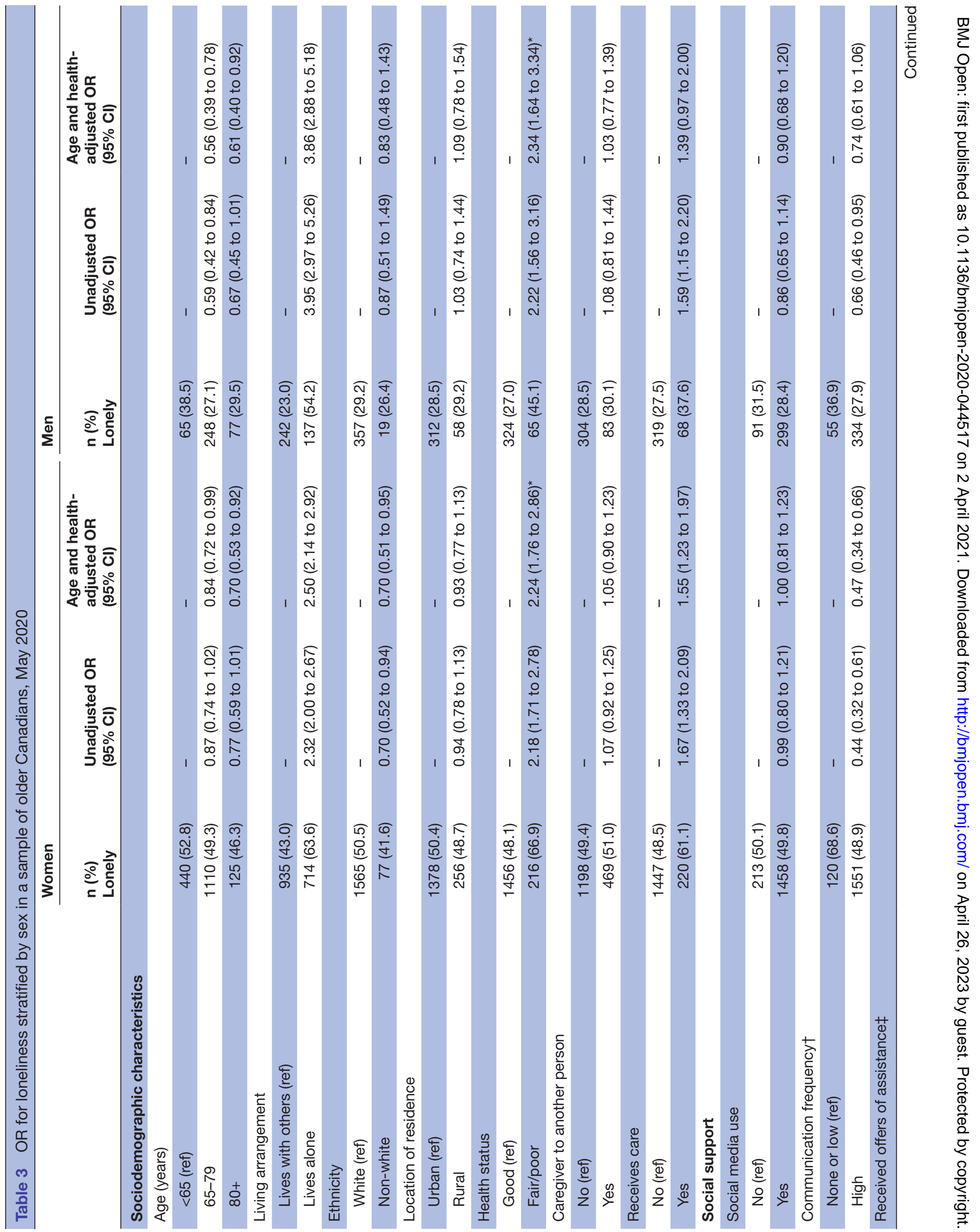




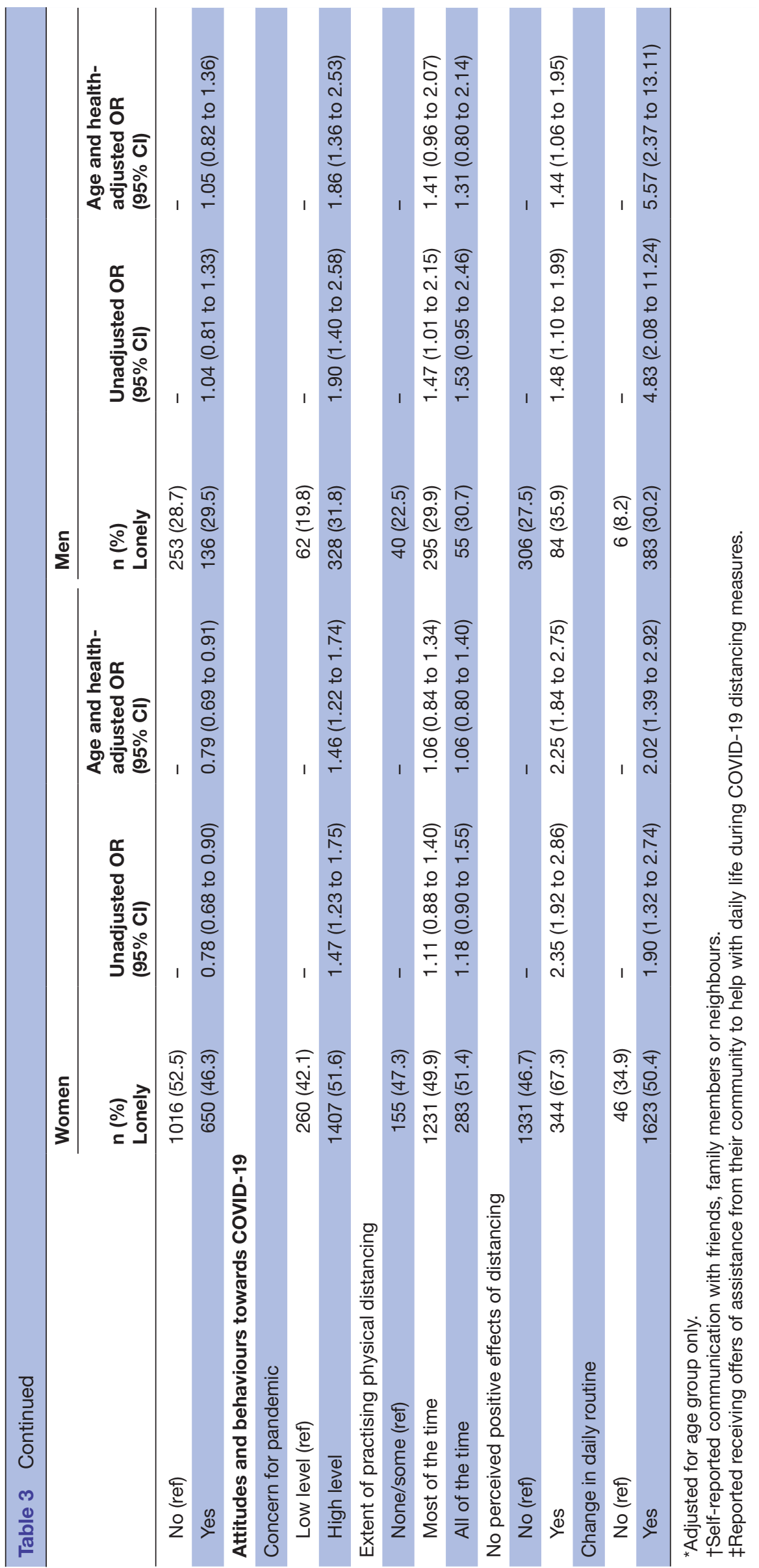


Table 4 OR for loneliness (sex pooled) in a sample of older Canadians, May 2020

\section{All respondents}

\begin{tabular}{|c|c|c|c|c|}
\hline & $\begin{array}{l}\text { Unadjusted } \\
\text { OR } \\
(95 \% \text { Cl) }\end{array}$ & $\begin{array}{l}\text { Age and sex- } \\
\text { adjusted } \\
\text { OR ( } 95 \% \mathrm{Cl})\end{array}$ & $\begin{array}{l}\text { Age, sex and } \\
\text { health status- } \\
\text { adjusted } \\
\text { OR }(95 \% \mathrm{Cl})\end{array}$ & $\begin{array}{l}\text { Fully* adjusted } \\
\text { OR }(95 \% \mathrm{Cl})\end{array}$ \\
\hline Female sex (ref male) & $2.44(2.13$ to 2.80$)$ & 2.38 (2.07 to 2.73$)$ & 2.41 (2.09 to 2.77$)$ & \\
\hline Women living alone & & & & $1.52(1.13$ to 2.04$)$ \\
\hline \multicolumn{5}{|l|}{ Age (years) } \\
\hline $65-79($ ref <65) & $0.74(0.64$ to 0.86$)$ & $0.81(0.70$ to 0.94$)$ & $0.78(0.67$ to 0.90$)$ & $0.69(0.59$ to 0.81$)$ \\
\hline $80+($ ref <65) & $0.61(0.49$ to 0.75$)$ & $0.79(0.63$ to 0.98$)$ & $0.72(0.57$ to 0.90$)$ & $0.50(0.39$ to 0.65$)$ \\
\hline Living alone & 2.83 (2.49 to 3.22$)$ & 2.78 (2.42 to 3.18$)$ & 2.74 (2.39 to 3.15$)$ & \\
\hline Rural & 0.98 (0.83 to 1.15$)$ & $0.95(0.81$ to 1.12$)$ & $0.96(0.82$ to 1.13$)$ & $1.07(0.90$ to 1.27$)$ \\
\hline Fair or poor health status & 2.14 (1.76 to 2.60$)$ & 2.25 (1.84 to 2.76$)$ & - & $1.93(1.54$ to 2.41$)$ \\
\hline Caregiver to another person & $1.14(1.00$ to 1.30$)$ & $1.04(0.91$ to 1.20$)$ & $1.05(0.91$ to 1.20$)$ & $1.18(1.02$ to 1.37$)$ \\
\hline Receives care & 1.54 (1.29 to 1.84$)$ & 1.76 (1.45 to 2.12$)$ & 1.50 (1.24 to 1.83$)$ & $1.47(1.19$ to 1.81$)$ \\
\hline \multicolumn{5}{|l|}{ Social support } \\
\hline Social media use & 1.08 (0.92 to 1.26$)$ & 0.93 (0.78 to 1.09$)$ & $0.96(0.81$ to 1.14$)$ & $1.13(0.94$ to 1.36$)$ \\
\hline High communication frequency & 0.65 (0.52 to 0.81$)$ & $0.53(0.42$ to 0.68$)$ & $0.57(0.45$ to 0.72$)$ & $0.55(0.43$ to 0.72$)$ \\
\hline Received offers of assistance & 0.89 (0.79 to 1.00$)$ & $0.85(0.75$ to 0.96$)$ & $0.85(0.75$ to 0.96$)$ & 0.79 (0.69 to 0.90$)$ \\
\hline \multicolumn{5}{|l|}{$\begin{array}{l}\text { Attitudes and behaviours towards } \\
\text { COVID-19 }\end{array}$} \\
\hline Reported change in routine & $2.36(1.72$ to 3.24$)$ & 2.30 (1.67 to 3.19$)$ & $2.50(1.80$ to 3.48$)$ & 2.81 (1.96 to 4.03$)$ \\
\hline
\end{tabular}

${ }^{*}$ Adjusted for all covariates listed in the table with an interaction term for sex and living alone $(p=0.006)$.

reporting feeling lonely some of the time and $8.3 \%$ feeling lonely always or often. More women reported feeling lonely than men and had higher odds of loneliness, despite controlling for factors hypothesised to contribute to sex differences including living alone, health status and caregiving. Our findings are similar to reports from the UK, where $22.4 \%$ and $4.1 \%$ of older adults reported feeling lonely sometimes or often, respectively, in the first 4 weeks of lockdown, ${ }^{32}$ and from the USA, where $13.8 \%$ (95\% CI $11.4 \%$ to $16.6 \%$ ) of adults aged $\geq 18$ years reported feeling lonely always or often at the beginning of April 2020. ${ }^{25}$

Living alone is as an important risk factor for loneliness, both pre-COVID-19 $9^{50} 41$ and during the pandemic. ${ }^{31-33}$ We found that living alone predicted loneliness in women and men, although the effect was greater in men. Physical distancing and stay-at-home measures are anticipated to have a greater toll for those living alone as they severely limit opportunities for face-to-face interaction to combat loneliness. ${ }^{33}$ The effect of living alone on loneliness may be greater in men because they tend to have fewer social contacts and close friends than women. ${ }^{354243}$ Indeed, male respondents in our survey communicated less frequently with family, friends and neighbours, and were less likely to seek out social connection to mitigate loneliness. Having a smaller social network may exacerbate some of the negative effects of living alone. Emerson recently found that older US adults who lived alone were less likely to have a close relationship that provided emotional security and well-being, and more likely to become 'more lonely' 
following the onset of COVID-19 than those living with others $(42.4 \%$ vs $27.9 \%) .{ }^{31}$ Alternatively, our finding may be due to the inherent overlap in the constructs of 'living alone' and 'marital status' because we partially captured the impact of being widowed or unmarried in men versus women. Prior research has shown that being single has a greater impact on men's loneliness, possibly explained by the fact that for many older men, their partners are their main confidante and source of intimacy. ${ }^{44} 45$

We found that older adults' perceptions and pandemic experiences were also associated with loneliness. Respondents who had a high level of concern for COVID-19, experienced changes to their daily routine and reported no perceived positive effects or 'silver livings' from the pandemic had increased odds of loneliness, while receiving offers of support and frequently communicating with family, friends and neighbours were protective. These findings underscore the importance of public health messages from the WHO targeted at older adults, including maintaining regular routines or creating new ones that include exercise, regular cleaning/chores and enjoyable activities; keeping in regular contact with loved ones; and restricting news consumption to specific times of day from reputable sources to reduce undue anxiety or distress. ${ }^{46}$

Family physician visits have been suggested as an important opportunity to screen for loneliness during COVID-19. ${ }^{47}$ Particular attention is recommended to be paid to patients who are older, live alone or have preexisting health conditions. ${ }^{47}$ Our findings suggest that considering the patient's sex, if they have sufficient social support and how the pandemic is affecting their daily routines could further assist in identifying at-risk individuals. Such questions would also be beneficial to align patients more purposefully with interventions. Virtual consultations and social prescribing (ie, linking patients with non-clinical supports in their community such as outdoor exercise classes, walking groups, virtual bereavement programmes, and so on) may be effective strategies to reduce loneliness during COVID-19 and beyond. ${ }^{47} 490$ Additionally, the Campaign to End Loneliness recently profiled psychological approaches, ${ }^{51}$ including cognitive-behavioural therapy (CBT) ${ }^{52}{ }^{53}$ mindfulness $^{54}$ and positive psychology, ${ }^{55}$ as promising interventions for addressing loneliness in older adults.

Lastly, technology can facilitate social connection and improve access to psychological interventions in the midst of physical distancing measures. ${ }^{49}{ }^{56}$ For older adults experiencing social loneliness as a result of being disconnected from their social network, websites or apps such as FaceTime and Zoom can connect them to family and friends and provide continuity of group activities such as exercise classes, spiritual services, and so on. ${ }^{57}$ These platforms can similarly enable access to virtual CBT and other psychological supports. ${ }^{57}$ One important consideration, however, is that, in order to be effective, older adults must want to, know how to use, and have access to these technologies. ${ }^{57}$ Recent research shows that many older adults lack access to internet-enabled devices ${ }^{58}$ and are unready for comparable technologies (ie, video telemedicine visits) due to inexperience with technology or physical disability. ${ }^{59}$ Consistent with prior research ${ }^{31} 60$ and likely a function of electronic survey administration, we found high levels $(\sim 85 \%)$ of social media engagement, with no increased risk for loneliness overall or by age. Our findings suggest there is a large segment of the older adult population for whom digital media-based interventions may be effective for mitigating and alleviating loneliness. Services that teach older adults how to use and connect with family and friends through social media platforms may be valuable. ${ }^{61}$ The importance of offline connection, however, should not be forgotten-phoning parents or older neighbours, and extending offers of assistance can go a long way to making someone feel connected and visible. $^{62}$

A recent US study reported that $30.9 \%$ of older adults surveyed felt more lonely after COVID-19-related physical distancing was implemented.$^{31}$ Our estimates of loneliness were almost double that of the CLSA's collected between 2010 and 2015 using a similar age group and measurement approach (49.3\% of women and $27.1 \%$ of men aged $65-79$ years felt lonely some of the time vs $24.7 \%$ and $17.9 \%$, respectively, for adults aged $65-74$ years) ${ }^{2}{ }^{23}$ Comparisons should be made cautiously considering differences in study populations. Longitudinal studies provide the most robust evidence of temporal changes. Using data collected at three time points, Luchetti et al found that older adults were the only group studied that showed a slight increase in loneliness in late March 2020 after social distancing measures were implemented in the USA compared with the baseline assessment in January/February, although levels remained stable in April. ${ }^{33}$ The study found that this increase was driven primarily by unavailable social connections, rather than feelings of isolation. O'Connor et al similarly observed an increase in self-reported loneliness in adults aged $\geq 60$ years at two time points early in the pandemic but not in younger age groups, ${ }^{64}$ while other studies have reported no change in loneliness over the course of the first pandemic wave. ${ }^{26}{ }^{65}$ As we move through successive pandemic waves, it will continue to be important to consistently measure how rates of loneliness change across different age groups to assess the longer term effects of protracted physical distancing and stay-at-home measures. Such longitudinal studies will be vital to characterising trajectories, identifying drivers of change and determining at-risk populations who could benefit from additional support, including young adults, who have reported among the highest levels of loneliness during this pandemic. ${ }^{336465}$

\section{Limitations}

Our study leveraged a strong community-based partnership to obtain timely data from a large sample of older Canadians on the impacts of COVID-19 during the first wave but had several limitations. Given the cross-sectional study design, causation should not be inferred. Analyses 
were exploratory and intended to identify characteristics and circumstances associated with loneliness to help target supports to those who could benefit from them. The second limitation is that the data are based on a convenience sample of retired educational staff, who are not fully representative of the Canadian population. The perspectives of vulnerable groups who may be at greater risk for loneliness (eg, those with severe mental health illness, low income, no home internet access, and so on) are likely under-represented in this sample. As such, our findings may be a conservative estimate of loneliness. Finally, the measure of loneliness used in our study has not been validated; although our findings support its criterion validity.

\section{CONCLUSIONS}

While many older adults reported feeling lonely during the first wave of COVID-19, several characteristics-in particular being female and living alone-increased the odds of loneliness. These characteristics may help guide targeting interventions to reduce loneliness as the pandemic persists.

\section{Twitter Rachel D Savage @savagera}

Acknowledgements The study authors thank RTOERO staff who assisted in the survey and the members who completed the survey. Dr Rochon is the RTO/ERO Chair in Geriatric Medicine at the University of Toronto.

Contributors RDS, PAR and JG conceived the study and its design. RDS took the lead in the planning of the study and in writing the manuscript. JL, AL and JG contributed to data collection by creating, pretesting and administering the survey. WW performed the statistical analysis. RDS, SEB, SAC, JG, AG, CRR, NMS and PAR contributed to the content of the survey instrument. All authors contributed to the interpretation of the results and critically revised the final manuscript.

Funding The authors have not declared a specific grant for this research from any funding agency in the public, commercial or not-for-profit sectors.

Competing interests None declared.

Patient consent for publication Not required.

Ethics approval The Research Ethics Board at Women's College Hospital in Toronto, Canada, approved this study (2020-0051-E).

Provenance and peer review Not commissioned; externally peer reviewed. Data availability statement Data are available upon reasonable request.

Supplemental material This content has been supplied by the author(s). It has not been vetted by BMJ Publishing Group Limited (BMJ) and may not have been peer-reviewed. Any opinions or recommendations discussed are solely those of the author(s) and are not endorsed by BMJ. BMJ disclaims all liability and responsibility arising from any reliance placed on the content. Where the content includes any translated material, BMJ does not warrant the accuracy and reliability of the translations (including but not limited to local regulations, clinical guidelines, terminology, drug names and drug dosages), and is not responsible for any error and/or omissions arising from translation and adaptation or otherwise.

Open access This is an open access article distributed in accordance with the Creative Commons Attribution Non Commercial (CC BY-NC 4.0) license, which permits others to distribute, remix, adapt, build upon this work non-commercially, and license their derivative works on different terms, provided the original work is properly cited, appropriate credit is given, any changes made indicated, and the use is non-commercial. See: http://creativecommons.org/licenses/by-nc/4.0/.

\section{ORCID iDs}

Susan E Bronskill http://orcid.org/0000-0002-7341-0655

Paula A Rochon http://orcid.org/0000-0002-5973-4151

\section{REFERENCES}

1 Perissinotto CM, Cenzer S I, Covinsky KE. Loneliness in older persons: a predictor of functional decline and death. Arch Intern Med 2012;172:1078-83

2 Raina P, Wolfson C, Kirkland S. The Canadian longitudinal study on aging (CLSA) report on health and aging in Canada, 2018. Available: https://www.clsa-elcv.ca/doc/2639

3 Victor CR, Yang K. The prevalence of loneliness among adults: a case study of the United Kingdom. J Psychol 2012;146:85-104

4 National Academies of Sciences Engineering and Medicine. Social isolation and loneliness in older adults: opportunities for the health care system. in. Washington, DC: The National Academies Press, 2020.

5 Cohen-Mansfield J, Hazan H, Lerman Y, et al. Correlates and predictors of loneliness in older-adults: a review of quantitative results informed by qualitative insights. International Psychogeriatrics 2016;28:557-76.

6 Pinquart M, Sorensen S. Influences on loneliness in older adults: a meta-analysis. Basic App/ Soc Psych 2001;23:245-66.

7 Bott NT, Sheckter CC, Milstein AS. women's health, and gender equity: The value of well-timed caregiver support. JAMA Neurology 2017;74:757-8

8 Gender MMHPW. aging, and social policy. In: Handbook of Aging and the Social Sciences. Elsevier Inc 2011:323-35.

9 O'Rand AM, Shuey KM. Gender and the devolution of pension risks in the US. Current Sociology 2007;55:287-304.

10 Holt-Lunstad J, Smith TB, Baker M, et al. Loneliness and social isolation as risk factors for mortality: a meta-analytic review. Perspect Psychol Sci 2015;10:227-37.

11 Hoogendijk EO, Smit AP, van Dam C, Dam C, et al. Frailty combined with loneliness or social isolation: an elevated risk for mortality in later life. J Am Geriatr Soc 2020;68:2587-93.

12 Valtorta NK, Kanaan M, Gilbody S, et al. Loneliness and social isolation as risk factors for coronary heart disease and stroke: systematic review and meta-analysis of longitudinal observational studies. Heart 2016;102:1009-16.

13 Cacioppo JT, Hughes ME, Waite LJ, et al. Loneliness as a specific risk factor for depressive symptoms: cross-sectional and longitudinal analyses. Psychol Aging 2006;21:140-51.

14 Cacioppo JT, Hawkley LC, Thisted RA. Perceived social isolation makes me sad: 5-year cross-lagged analyses of loneliness and depressive symptomatology in the Chicago health, aging, and social relations study. Psychol Aging 2010;25:453-63.

15 Amieva H, Stoykova R, Matharan F, et al. What aspects of social network are protective for dementia? not the quantity but the quality of social interactions is protective up to 15 years later. Psychosom Med 2010;72:905-11.

16 Rafnsson SB, Orrell M, d'Orsi E. Loneliness, social integration, and incident dementia over 6 years: prospective findings from the English longitudinal study of ageing. The journals of gerontology Series B, Psychological sciences and social sciences 2017.

17 Peplau LA, Perlman D. Loneliness: A sourcebook of current theory, research and therapy. New York: John Wiley, 1982.

18 Stall NM, Savage RD, Rochon PA. Loneliness in older adults. Can Med Assoc J 2019;191:E476.

19 Hawryluck L, Gold WL, Robinson S, et al. SARS control and psychological effects of quarantine, Toronto, Canada. Emerg Infect Dis 2004;10:1206-12.

20 Brooks SK, Webster RK, Smith LE, et al. The psychological impact of quarantine and how to reduce it: rapid review of the evidence. Lancet 2020;395:912-20.

21 Xiong J, Lipsitz O, Nasri F, et al. Impact of COVID-19 pandemic on mental health in the general population: a systematic review. $J$ Affect Disord 2020;277:55-64.

22 Tull MT, Edmonds KA, Scamaldo KM, et al. Psychological outcomes associated with Stay-at-Home orders and the perceived impact of COVID-19 on daily life. Psychiatry Res 2020;289:113098.

23 Buecker S, Horstmann KT, Krasko J. Changes in daily loneliness for German residents during the first four weeks of the COVID-19 pandemic. Social science \& medicine 2020;113541.

24 Kotwal AA, Holt-Lunstad J, Newmark RL. Social isolation and loneliness among San Francisco Bay area older adults during the COVID-19 Shelter-in-Place orders. J Am Geriatr Soc 2020.

25 McGinty EE, Presskreischer R, Han $\mathrm{H}$, et al. Psychological distress and loneliness reported by US adults in 2018 and April 2020. JAMA 2020;324:93.

26 Niedzwiedz CL, Green MJ, Benzeval M. Mental health and health behaviours before and during the initial phase of the COVID-19 lockdown: longitudinal analyses of the UK household longitudinal study. J Epidemiol Community Health 2020. 
27 Wang C, Pan R, Wan X, et al. Immediate psychological responses and associated factors during the initial stage of the 2019 coronavirus disease (COVID-19) epidemic among the general population in China. Int J Environ Res Public Health 2020:17:1729.

28 Rossi R, Socci V, Talevi D, et al. COVID-19 pandemic and Lockdown measures impact on mental health among the general population in Italy. Front Psychiatry 2020;11:790.

29 Nelson LM, Simard JF, Oluyomi A, et al. Us public concerns about the COVID-19 pandemic from results of a survey given via social media. JAMA Intern Med 2020;180:1020.

30 Wolf MS, Serper M, Opsasnick L, et al. Awareness, attitudes, and actions related to COVID-19 among adults with chronic conditions at the onset of the U.S. outbreak: a cross-sectional survey. Ann Intern Med 2020;173:100-9.

31 Emerson KG. Coping with being cooped up: social distancing during COVID-19 among 60+ in the United States. Revista panamericana de salud publica = Pan American journal of public health 2020;44:e81

32 LZ L, Wang S. Prevalence and predictors of general psychiatric disorders and loneliness during COVID-19 in the United Kingdom. Psychiatry research 2020;291:113267.

33 Luchetti M, Lee $\mathrm{JH}$, Aschwanden $\mathrm{D}$, et al. The trajectory of loneliness in response to COVID-19. Am Psychol 2020;75:897-908.

34 van Tilburg TG, Steinmetz S, Stolte E, et al. Loneliness and mental health during the COVID-19 pandemic: a study among Dutch older adults. J Gerontol B Psychol Sci Soc Sci 2020;29.

35 Dahlberg L, Andersson L, McKee KJ, et al. Predictors of loneliness among older women and men in Sweden: a national longitudinal study. Aging Ment Health 2015;19:409-17.

36 Eysenbach G. Improving the quality of web surveys: the checklist for reporting results of Internet E-Surveys (cherries). J Med Internet Res 2004:6:e34.

37 Office for National Statistics. Measuring loneliness: guidance for use of the national indicators on surveys. [Internet], 2018. Available: https://www.ons.gov.uk/peoplepopulationandcommunity/wellbeing/ methodologies/measuringlonelinessguidanceforuseofthenationalin dicatorsonsurveys [Accessed 16 Jul 2020].

38 Canada S. Canadian Community Health Survey (CCHS) - 2019. [Internet], 2019. Available: https://www23.statcan.gc.ca/imdb/ p3Instr.pl?Function $=$ assemblelnstr\& $a=1$ \&\&lang $=$ en\&ltem $I d=$ 1207185\#qb1208869 [Accessed 6 Jul 2020].

39 Dillman DA, Smyth JD, Christian LM. Internet, mail, and mixed-mode surveys: the tailored design method. 3rd edn. Hoboken, NJ, US: John Wiley \& Sons Inc, 2009.

40 Menec VH, Newall NE, Mackenzie CS, et al. Examining individual and geographic factors associated with social isolation and loneliness using Canadian longitudinal study on aging (CLSA) data. PLoS One 2019;14:e0211143.

41 Gierveld JdeJ. A review of loneliness: concept and definitions, determinants and consequences. Rev Clin Gerontol 1998;8:73-80.

42 Victor CR, Scambler SJ, Marston L, et al. Older People's Experiences of Loneliness in the UK: Does Gender Matter? Social Policy and Society 2006;5:27-38.

43 Dykstra PA, Fokkema T. Social and emotional loneliness among Divorced and married men and women: comparing the deficit and cognitive perspectives. Basic App/ Soc Psych 2007;29:1-12.

44 Nicolaisen $\mathrm{M}$, Thorsen $\mathrm{K}$. Loneliness among men and women - a five-year follow-up study. Aging Ment Health 2014;18:194-206.

45 Antonucci TC, Akiyama H. An examination of sex differences in social support among older men and women. Sex Roles 1987; $17: 737-49$.

46 World Health Organization. Mental health and psychosocial considerations during the COVID-19 outbreak, 2020. Available: https://www.who.int/docs/default-source/coronaviruse/mentalhealth-considerations.pdf?sfvrsn=6d3578af_2 [Accessed July 14 2020]

47 Razai MS, Oakeshott P, Kankam H, et al. Mitigating the psychological effects of social isolation during the covid-19 pandemic. BMJ 2020;369:m1904

48 Killgore WDS, Cloonan SA, Taylor EC, et al. Loneliness: a signature mental health concern in the era of COVID-19. Psychiatry Res 2020;290:113117.

49 Galea S, Merchant RM, Lurie N. The mental health consequences of COVID-19 and physical distancing: the need for prevention and early intervention. JAMA internal medicine 2020.

50 Roland M, Everington S, Marshall M. Social prescribing transforming the relationship between physicians and their patients. N Engl J Med 2020;383:97-9.

51 Campaign to End Loneliness. The psychology of loneliness: why it matters and what we can do, 2020. Available: https://www.campaign toendloneliness.org/wp-content/uploads/Psychology_of Loneliness FINAL_REPORT.pdf [Accessed 18 Dec 2020].

52 Cohen-Mansfield J, Hazan H, Lerman Y, et al. Efficacy of the I-SOCIAL intervention for loneliness in old age: lessons from a randomized controlled trial. J Psychiatr Res 2018;99:69-75.

53 Jarvis MA, Padmanabhanunni A, Chipps J. An evaluation of a low-intensity cognitive behavioral therapy mHealth-Supported intervention to reduce loneliness in older people. Int J Environ Res Public Health 2019:16:1305.

54 Creswell JD, Irwin MR, Burklund LJ, et al. Mindfulness-Based stress reduction training reduces loneliness and pro-inflammatory gene expression in older adults: a small randomized controlled trial. Brain Behav Immun 2012;26:1095-101.

55 Lim MH, Rodebaugh TL, Eres R, et al. A pilot digital intervention targeting loneliness in youth mental health. Front Psychiatry 2019;10:604

56 Merchant RM, Lurie N. Social media and emergency preparedness in response to novel coronavirus. JAMA 2020;323:2011.

57 Conroy KK, Mittelstaedt Srikripa;, Stacy; Patel S. Technological advancements to address elderly loneliness: practical considerations and community resilience implications for COVID-19 pandemic, 2020. Available: https://dash.harvard.edu/handle/1/37364389

58 Roberts ET, Mehrotra A. Assessment of disparities in digital access among Medicare beneficiaries and implications for telemedicine. JAMA Intern Med 2020;180:1386.

59 Lam K, Lu AD, Shi Y, et al. Assessing telemedicine Unreadiness among older adults in the United States during the COVID-19 pandemic. JAMA Intern Med 2020;180:1389.

60 Stockwell S, Stubbs B, Jackson SE, et al. Internet use, social isolation and loneliness in older adults. Ageing Soc 2020;57:1-24.

61 Ibarra F, Baez M, Cernuzzi L, et al. A systematic review on Technology-Supported interventions to improve old-age social wellbeing: loneliness, social isolation, and connectedness. J Healthc Eng 2020;2020:1-14.

62 Seifert A. The digital exclusion of older adults during the COVID-19 pandemic. J Gerontol Soc Work 2020;63:674-6.

63 Raina P, Wolfson C, Kirkland S, et al. Cohort profile: the Canadian longitudinal study on aging (CLSA). Int J Epidemiol 2019;48:1752-3.

64 O'Connor RC, Wetherall K, Cleare S, et al. Mental health and wellbeing during the COVID-19 pandemic: longitudinal analyses of adults in the UK COVID-19 Mental Health \& Wellbeing study. The British Journal of Psychiatry 2020;57:1-8.

65 Bu F, Steptoe A, Fancourt D. Loneliness during a strict lockdown: trajectories and predictors during the COVID-19 pandemic in 38,217 United Kingdom adults. Soc Sci Med 2020;265:113521. 